\title{
Advanced Courtroom Skills
}

\section{An intensive training course for the professional giving evidence in court}

This day long course for four to six participants is designed to help you give a clear, confident, and professional presentation of your testimony in Court and to do justice to your submission and to the work you have done prior to the hearing.

You learn how to prepare yourself for attendance in Court, how to recognise the techniques lawyers use and the strategies that can be developed to handle cross-examination effectively, and how to deliver your evidence well.

The setting is informal and experiential, with modelling, role playing and feedback. The partici- pants are usually from different disciplines and, as a finale, each presents a pre-prepared case in 'Court'.

Advanced Courtroom Skills is educationally sound, well presented, enjoyable, and is flexible enough to be of practical value to psychiatrists of differing levels of experience faced with the prospect of going to court.

Further information: Catherine Bond, Bond Solon Solicitors, 69 Walcot Square, London SE11 4UB (telephone 071582 3848; fax 071820 1714).

\section{Tell me why}

Planning happens in a void At dizzy heights with no ascent For lesser mortals who nevertheless Passionately care and believe

In the nurture of a fine institution Which formed our inheritance, From a man with visionary Social conscience,

Now piecemeal dismantled Under the guise of quality, efficiency Backed by mountains of missives And armies of human resources.
Well the hidden agenda must gestate

As a queen fed diligently

By myriad workers programmed To behave,

While Hannibal the Cannibal secures The silence of the lambs and a crumbling legacy is audited to death

R. H. BRADWELL (Consultant on Psychiatry of Old Age and Clinical Director of Elderly Mental Health Service, Doncaster Royal Infirmary) 